\title{
Consulting revenue sharing, auditor effort and independence, and the regulation of auditor compensation
}

\author{
by \\ Xiaohong Liu* and Derek K. Chan \\ School of Business \\ The University of Hong Kong
}

Current Version: August 2011

Key Words: Regulation of Auditor Compensation; Sharing Rules of Audit Firms; Auditor Effort; Truthful Reporting.

Classification Codes: M41, M42, E61

\footnotetext{
* We appreciate the helpful comments by Tim Baldenius, Jerry Feltham, Katherine Schipper, Reed Smith (discussant), and seminar participants at the University of British Columbia, the Chinese University of Hong Kong, the University of Hong Kong, Nanjing University, the 2006 HKUST Summer Symposium on Accounting Research, the 2006 European Accounting Association Conference, the 2008 SMU-HKUSTSNU joint research camp, and the 2008 AAA Annual meeting.

Correspondence: Xiaohong LIU, School of Business, The University of Hong Kong, Pokfulam Road, HONG KONG. Tel: (852) 2219 4216; Fax: (852) 2858 5614; Email: acliu@hku.hk.
} 


\title{
Consulting Revenue Sharing, Auditor Effort and Independence, and the Regulation of Auditor Compensation
}

\begin{abstract}
The joint provision of audit and non-audit services by audit firms to their audit clients has posed a threat to auditor independence. To mitigate the independence problem, the U.S. Securities and Exchange Commission (SEC) issued a regulation (SEC 2003) that prohibits audit partners from receiving compensation for the sale of non-audit services to their audit clients. This study examines the effects of this regulatory change on the effort and reporting decisions of audit partners. We show that partners in an audit firm strategically change the firm's liability-sharing rule. As a consequence, the regulation restores truthful reporting but has an undesirable negative effect on audit effort. The effect of the regulation on the welfare of the economy (defined as the total payoff to both audit firms and their clients) hinges on the tradeoff between the benefit of the regulation, which is derived from the inducement of truthful reporting, and the cost of the regulation, which results from less diligent audit work. We show that the regulation is more likely to increase the welfare in a strong legal regime (where the legal liability cost of auditor litigation is high) than in a weak legal regime.
\end{abstract}

Keywords: Regulation of Auditor Compensation; Sharing Rules of Audit Firms; Auditor Effort; Truthful Reporting.

Classification Codes: M41, M42, E61. 


\section{Introduction}

Providing non-audit (consulting) services to audit clients continues to be a common practice for audit firms. For some clients, non-audit fees exceed the audit fees paid to their audit firms. The joint provision of audit and non-audit services can help an audit firm gain advantages as a result of the collaboration between the audit and consulting divisions within the firm. However, these advantages may also compromise auditor independence. For fear of losing large non-audit revenues, auditors may issue unwarranted audit opinions. ${ }^{1}$ To address the independence problem, the U.S. Securities and Exchange Commission (SEC) issued a regulation (SEC 2003, Section 2E) related to auditor compensation. This regulation "prohibits accounting firms from establishing an audit partner's compensation or allocation of partnership 'units' based on the sale of non-audit services to the partner's audit clients." 2 The objective of this study is to examine the effects of this regulatory change on the effort and reporting decisions of audit partners.

To examine the issue of partner compensation, we develop a stylized model in which an audit firm (partnership) consists of an audit partner and a consulting partner that perform audit and consulting tasks, respectively, for audit clients (shareholders). The partners choose a (linear) sharing rule that determines how they share the audit and consulting fee revenues and the legal liability costs of auditor litigation. The consulting partner enjoys a competitive cost advantage over an outside consultant in performing the consulting task for the firm's audit client. This is consistent with the notion that there are economies of scope in the provision of audit and non-audit services within an audit firm. These economies

\footnotetext{
${ }^{1}$ Enron paid its auditor, Arthur Andersen, \$27 million for consulting services in 2000, which accounted for more than half of the total fees that it paid to the audit firm (see Benston and Hartgraves 2002 and Kaplan 2004). These large consulting fees were likely to have created a serious conflict of interest for Arthur Andersen.

${ }^{2}$ See the SEC (2003) rule titled Strengthening the commission's requirements regarding auditor independence.
} 
of scope arise from the knowledge shared about the companies being audited and other infrastructural elements (SEC 2003, Section 4C-1a). ${ }^{3}$

When the audit firm's consulting profit is less than the expected legal liability cost of an audit failure, auditor independence is not an issue, so the analyses focus on the opposite, more interesting case. In the case where the consulting profit exceeds the expected legal liability cost, the audit firm (i.e., partners as a whole) has an incentive to suppress evidence of financial misstatements and issue an unqualified opinion. This case provides an interesting setting to examine the issue of auditor independence and is particularly relevant in the light of actual observations. For instance, in a testimony before the U.S. Senate in 2002, the former SEC chairman Arthur Levitt commented that "As auditing becomes an ever-smaller portion of a firm's business with an audit client, it becomes harder to assume that the auditor will challenge management when he or she should, if to do so might jeopardize a lucrative consulting contract for the auditor's firm." Similarly, after being brought into Arthur Andersen to help overhaul the firm, the former Federal Reserve chairman Paul Volcker concluded that the solution to the auditing crisis would be to provide audit clients with audit services only and nothing else (Revell 2003). Consistent with these comments, Congress and the SEC held the view that large consulting revenues would impair auditor independence and promulgated the Sarbanes-Oxley Act (SOX 2002) and the SEC (2003) rules to help restore auditor independence.

The main findings of this paper are as follows. Even though the audit task and the consulting task are performed by different partners in an audit firm, the firm's optimal sharing rule is such that the audit partner's compensation must depend on the consulting revenues. This is explained by the fact that the firm's optimal sharing rule induces the partners to take actions that maximize the firm's

\footnotetext{
${ }^{3}$ In this study, we refer "firm" to the audit firm and "company" to the company being audited.
} 
overall payoff (which is the joint payoff of the partners). If the audit partner does not share any of the consulting revenues, then the personal payoff that the audit partner receives from a client will not fully incorporate the consulting profits (but the firm's payoff will). As a consequence, the audit partner's effort and reporting decisions will be sub-optimal from the firm's point of view. Thus, the optimal sharing rule awards the audit partner an appropriate proportion of the consulting revenues to align the audit partner's personal payoff with the firm's payoff. Such a sharing rule induces the audit partner to select the effort level and reporting strategies that are optimal for the partnership as a whole.

Under the optimal sharing rule, the audit partner has an incentive to suppress evidence of misstatements in pursuit of consulting profits. The lack of auditor independence results in shareholders investing in companies that have issued misstated financial reports in which shareholders would not have invested had the auditor reported truthfully. This leads to a loss in the welfare of the economy (which is defined as the total payoff of audit firms and shareholders). ${ }^{4}$ The lack of auditor independence provides the rationale for the government to intervene in the compensation structure of audit firms.

The SEC (2003) regulation prohibits audit partners from receiving consulting fees. Conventional wisdom suggests that this regulation should induce auditors to report truthfully and work harder, as any advantages (i.e., consulting profits) of not finding and reporting evidence of misstatements are gone. Hence,

\footnotetext{
${ }^{4}$ The lack of independence in a broader sense includes two issues. The first is the issue of an auditor exerting a low level of effort to verify a financial report (and thus being less likely to detect any material misstatement in it). The second issue is the lack of truthful reporting, or the adoption of a reporting strategy in which an auditor issues an unqualified opinion despite finding evidence of misstatements. Lack of independence in a narrow sense refers only to the latter reporting strategy. In this study, both independence issues (the auditor's effort choice and reporting strategy) are examined, but the term "independence" refers only to "truthful reporting" to remain consistent with the use of the term in previous studies such as DeAnglo (1981), Magee and Tseng (1990), and Simunic (1984).
} 
the welfare of the economy would increase. However, we find that while the regulation restores truthful reporting, it has an unexpected negative effect on audit effort.

The regulation has unintended consequences on audit effort because it is only concerned with the revenue-sharing rule, but not the liability-sharing rule. Our analysis shows that while the partners of the firm change their consulting revenue-sharing rule to comply with the regulation, they also strategically change their liability-sharing rule. Before the regulation was introduced, the audit partner suppressed evidence of misstatements for the companies to which the audit firm also supplied consulting services, and thus also received the consulting profits from those companies. After the regulation, the audit partner reports truthfully regardless of whether consulting services are provided. Truthful reporting causes the firm to forgo the consulting profits from the companies for which the audit partner has detected financial misstatements. To pursue profitable consulting businesses, the partners of the firm strategically change the liability-sharing rule to induce a lower level of audit effort by reducing the portion of legal liability that the audit partner must bear.

The reduction in the audit partner's effort allows the firm to pursue profitable consulting businesses, but results in an undesirable negative effect on the welfare of the economy. Therefore, whether the regulation improves welfare depends on the tradeoff between the welfare loss that is associated with the reduced audit effort and the welfare gain that is provided by the inducement of truthful reporting. We find that the regulation is more likely to increase welfare in a strong legal regime (where the legal liability cost of auditor litigation is high) than in a weak legal regime. When the legal regime is sufficiently strong, the effort-reducing effect of the regulation becomes insignificant compared with the welfare gain that is afforded by truthful reporting, which leads to an overall improvement in welfare. 
The SEC (2003) regulation, however, contains the following modifier: "This rule does not preclude an audit partner from sharing in the profits of the overall firm... and an audit partner's evaluation could take into account a number of factors directly or indirectly related to selling services to an audit client." While our main analysis assumes that the SEC regulation forces the audit partner to receive zero consulting revenues, we provide additional analysis in Section 4.1 which shows that this modifier may allow an audit partner's compensation to vary indirectly with the consulting revenues, thus causing the same independence problem as before the regulation. This implies that the effectiveness of the regulation depends on the ability of the regulatory body to forbid an audit partner's compensation from varying with the consulting revenues either directly or indirectly. For the latter, the regulation should not allow audit partners to be evaluated based on selling non-audit services to audit clients.

The basic audit technology used in this study is the same as that used in Dye (1993, 1995), Schwartz (1997), and Pae and Yoo (2001). Whereas those studies assume truthful reporting to focus on the audit effort choice, this study considers both the effort and reporting decisions and characterizes how one depends on the other. Thus, in this study, the welfare of the economy may be impaired when the audit partner suppresses evidence of misstatements or makes insufficient effort in the performance of audits. This study is also related to that of Liu and Simunic (2005). Both studies consider the relationship between the partnership's sharing rule and the production decisions of individual partners. Whereas Liu and Simunic (2005) examine the sharing rule between audit partners, this study focuses on the sharing rule between the audit and consulting partners and examines the effect of the regulation of auditor compensation on partner

\footnotetext{
5 "For example, an audit partner could be evaluated on the complexity of his or her engagements, the overall management of the relationship with an audit client including the provision of nonaudit services, and/or the attainment of explicit sales goals." (SEC 2003, Footnote 178)
} 
behavior.

Chan (2009) also finds a decrease in auditor effort following regulatory changes. This study differs from Chan (2009) in two important ways. First, this study analyzes the regulation related to auditor compensation, whereas Chan (2009) analyzes a regulation that limits the scope of consulting services. Second, this study explores the effects of the sharing rule of audit firms on partner behavior, whereas Chan (2009) does not consider the sharing rule and treats the audit firm as a single auditor.

This study contributes to the literature that seeks to understand the implications of the SEC regulations that were formulated under SOX. The assumption underlying the SEC's 2003 regulation on auditor compensation is that large non-audit services impair auditor independence. Most of the studies on nonaudit services focus on the validity of this assumption (e.g., Ascioglu, Hegde, and McDermott 2005, Asare, Cohen, and Trompeter 2005, Ghosh, Kallapur, and Moon 2009). ${ }^{6}$ There has been no prior study that offers a rigorous analysis of the impact of the SEC regulation on auditor behavior. Our study fills this gap in the literature. We show that if the assumption underlying the SEC regulation holds, i.e., if the large non-audit fees impair auditor independence, then the regulation restores truthful reporting but may have unintended consequences on auditor effort. $^{7}$ Our results provide new insights into the effects of the regulation on auditor independence, auditor effort, and the welfare of the economy.

Section 2 presents the model. Section 3 shows the optimal (linear) sharing rules for audit firms, various decisions made by partners, and the welfare of the economy before and after the regulation of auditor compensation came into effect.

\footnotetext{
${ }^{6}$ See Ascioglu, Hegde and McDermott (2005) for a literature review of the mixed empirical evidence on whether non-audit revenues impair auditor independence.

${ }^{7}$ Our unreported analysis also examines the alternative case, in which the SEC assumption does not hold, i.e., when the non-audit revenues do not affect auditor independence. In that case, while the SEC regulation (2003) on auditor compensation changes the firm's sharing rule, it has no effect on audit partner behavior.
} 
Section 4 provides relevant discussions. Section 5 concludes. A table of notations appears in Appendix A. All of the proofs appear in Appendix B.

\section{The Model}

We consider a one-period model in which two identical audit firms, Firms $\mathrm{A}$ and $\mathrm{B}$, compete to provide audit and consulting services to $n>0$ identical companies. ${ }^{8}$ Each audit firm is a partnership that consists of an audit partner and a consulting partner who perform audit and consulting tasks, respectively, under the name of their firm. ${ }^{9}$ All of the parties in the model are risk neutral, and the interest rate is normalized to zero. ${ }^{10}$

\subsection{Shareholders’ Investment Opportunities}

Each of the $n$ companies is owned by shareholders and operated by a manager. The continued operation of each company requires an investment of $I>$ 0 from its shareholders at the beginning of the period. The productivity of each company depends on its manager's competence, which can be either high or low

\footnotetext{
${ }^{8}$ The consideration of the oligopolistic competition of audit firms will make the paper more complex and less focused, but should not change the main results of the paper. For example, to consider industry specialization, a new stage can be added in which firms invest in the development of industry expertise before they set profit-sharing rules. In equilibrium, firms invest in different industry expertise, such that auditors from different firms specialize in auditing different companies as they have a cost advantage in auditing the companies in which they specialize (see Chan 1999). However, the main results of the paper, i.e., the choice of the sharing rule of audit and consulting partners within an audit firm and the results of the welfare analysis, should remain unchanged.

${ }^{9}$ In practice, an audit firm is often organized as a partnership in which the partners practice in the different divisions of auditing and consulting. While most of the national audit firms are limited liability companies (LLCs), the sharing rule among partners in an LLC is similar to that in a partnership. In this study, the audit firms have sufficient wealth to cover legal payments ordered by a court. Relaxing this assumption will not qualitatively change our analysis, but requires relabeling the audit firm's legal liability by the lower amount between the legal payment ordered by the court and the incorporated wealth of the audit firm.

${ }^{10} \mathrm{We}$ assume risk-neutrality for tractability of analysis. The analysis will not be tractable with risk aversion as there are infinite contingencies to consider. This is a limitation shared by most of the analytical auditing papers, with only a few exceptions that focus on a few tractable events (Balachandran and Ramakrishnan 1987).
} 
but is unknown to the shareholders. The common prior probability of the manager having a high level of competence is $p \in(0,1)$. If the manager has a high level of competence, then the company will generate a cash flow of $R>0$. In contrast, if the manager has a low level of competence, then the company will generate $R$ with a probability of $\varphi \in(0,1)$ and zero with the complementary probability. If the shareholders do not make the required investment, they will liquidate the company and obtain a zero return. ${ }^{11}$

We assume that a correctly stated financial report of the company would allow the shareholders to learn about the manager's competence. A financial report, such as an income statement, reflects the past performance of the manager and therefore is a useful indicator of the manager's competence. We further assume that the manager obtains personal benefits from the continued operation of the company and thus always presents to shareholders a financial report that indicates a high level of competence. ${ }^{12}$ In other words, the financial report of a highly competent manager is correctly stated, but that of an incompetent manager is misstated.

\subsection{Audit and Consulting Services}

Each company is mandated to hire an auditor to perform an audit to verify the credibility of the financial report that has been prepared by the manager. ${ }^{13}$ In our model, the audit client (i.e., the user of the auditor's report) is the shareholders of the company. This is consistent with SOX, which mandates that the audit

\footnotetext{
${ }^{11}$ Alternatively, we could assume that the liquidating value of the company is non-zero and varies with manager type, but this would complicate the notation without qualitatively affecting the analysis.

${ }^{12}$ Such personal benefits include the business experience and skills gained from operating a company, the diversion of cash flows from the company, and other job-related perks. The agency problem between the shareholders and the manager is exogenously assumed in this model.

${ }^{13} \mathrm{We}$ assume a mandatory audit for simplicity. This assumption is innocuous as one can always find conditions under which the audit has a positive value in equilibrium.
} 
committee (which represents the interests of shareholders) should be responsible for the hiring and firing of auditors.

An audit can be viewed as a two-step process. In the first step, the audit partner expends effort on inspecting and analyzing the financial report, thereby obtaining evidence for the audit. Formally, let $e \in[0,1]$ be the audit (inspection) effort and $k e^{2}$ be the cost of the audit effort, where $k>0$. We adopt the common assumption in the audit literature (e.g., Dye 1993, 1995; Pae and Yoo 2001) that the audit technology is succinctly represented by the following conditional probabilities:

$$
\left\{\begin{array}{l}
\operatorname{Pr}(\text { no evidence of mistatement } \mid \text { correct, } e)=1, \text { and } \\
\operatorname{Pr}(\text { evidence of misstatement } \mid \text { incorrect, } e)=e .
\end{array}\right.
$$

"Pr" denotes probability, "correct" means that the financial report is correctly stated, and "incorrect" means that the financial report contains material misstatements. In words, (1) states that if the financial report is correctly stated, the audit partner will not find evidence of misstatements. If the financial report is misstated, the probability that the audit partner will find evidence of misstatements increases with the inspection effort.

After the audit partner selects effort $e$ but before issuing an audit opinion, a consulting task becomes known to the audit partner with a probability $\theta \in(0,1) .{ }^{14}$ We assume that the auditor selects audit effort before the consulting opportunity is known to capture the scenario in which the consulting opportunity

\footnotetext{
${ }^{14}$ This assumption captures the scenario in which, in the course of doing business, the company's management or auditor learns whether and how the company's operations and information systems can be improved so that the company can operate more efficiently in the future. The management may seek the services of a consultant to make such improvements in the future.
} 
is not fully anticipated when the auditor performs the audit. ${ }^{15}$ The consulting task will improve the profitability of the company if the shareholders decide to continue to operate the company by making a new investment. Specifically, we assume that the consulting task will generate a cash flow of $\pi>0$ for the shareholders. We assume that $\varphi R+\pi<I<p R$. This implies that, while a company is worth investing in when information about the type of manager is not known, it is not worth investing in, even with the benefits of consulting, if the shareholders know that the manager has a low level of competence.

In the second step of the audit, the audit partner issues an opinion about the credibility of the financial report. When the audit partner obtains no evidence of misstatements, he will issue an unqualified opinion, as he cannot fabricate evidence to report otherwise. However, when the audit partner obtains evidence of misstatements, he has the option of either suppressing the evidence by issuing an unqualified opinion, or revealing the evidence by issuing a qualified opinion. In the latter case, the reason for the qualification must be shown in the audit report. Thus, a qualified opinion must indicate that the financial report contains material misstatements. Neither the audit partner's effort nor the unreported audit evidence is publicly observable.

After observing the audit opinion (i.e., the output of the audit), the shareholders decide whether to continue to operate or liquidate the company. The shareholders understand that the audit partner is strategic in both effort and reporting decisions, and take that into account when making investment decisions. The audit opinion offers a level of assurance, albeit imperfect, that the financial report is free of misstatements. The level of assurance can be interpreted as audit

\footnotetext{
${ }^{15}$ Our unreported analysis under the alternative assumption that the auditor knows about consulting opportunities before selecting audit effort, shows that the essence of the main results of this study is not sensitive to this alternative assumption, except that the auditor will always report truthfully and the issue of auditor independence will be fully captured by the auditor's effort choice.
} 
quality.

A few more assumptions about the consulting task are as follows. First, we assume that the output of consulting services, such as tax returns, accounting policy consultation, and various assessments and advice, is contractible. Second, we assume that the consulting partner has a cost advantage in performing consulting tasks for the firm's audit clients over a consultant from outside the audit firm. This cost advantage stems from the sharing of information about the company that has been collected and documented by the audit partner. This information helps the consulting partner to understand the company's organizational structures, operations, and accounting systems. ${ }^{16}$ Specifically, the effort cost of performing the consulting work is $r$ by an outside consultant and $v$ by the consulting partner, and $\pi>r>v>0$. We assume that the knowledge transfer from audit partners to consulting partners is frictionless and costless within an audit firm. ${ }^{17}$

Audit failure is defined as a situation in which the audit partner issues an unqualified opinion on a misstated financial report. A strict liability regime is assumed so that when the company fails, the audit firm is held liable for the audit failure. ${ }^{18}$ The company fails when its cash flow realized at the end of the period is

\footnotetext{
${ }^{16}$ According to Statements on Auditing Standards No. 108 and 114 (AU§311), once an audit engagement has been accepted, the auditor must obtain sufficient knowledge about the company to understand the events and transactions that affect the financial report. This includes knowledge of the nature of the company's business and industry, its accounting policies, levels of control, and other risks that are likely to cause accounting problems. This knowledge is necessary for the auditor to inspect the financial report effectively and will also help the consulting partner to perform consulting tasks.

${ }^{17}$ The alternative assumption that the internal knowledge transfer is costly for the audit partner will not qualitatively change the results of this study as long as the audit firm as a whole has a cost advantage compared with an outside consulting firm.

${ }^{18}$ For simplicity, we assume a strict legal liability regime. Our sensitivity analysis under the alternative assumption of a due care regime finds that the complexity of the analysis increases but the main insights offered in this paper remain unchanged. The details are not reported for brevity. Our model does not include deadweight litigation costs of shareholders and auditors. See Smith and Tidrick (1997) and Zhang and Thoman (1999) for the examination of the shareholders' litigation strategy and its impact on the auditor's decision.
} 
zero (without the benefit of consulting services) or $\pi$ (with the benefit of consulting services). The legal payment for this failure by the audit firm to the client is denoted by $l>0 .{ }^{19}$

\subsection{Sharing Rules of Audit Partnerships}

In our model, an audit firm is not a person but a decentralized organization in which individual partners perform different tasks while sharing the audit and consulting fee revenues and the legal liability costs according to a sharing rule. At the beginning of the game, the audit partner and the consulting partner in each firm negotiate and choose an optimal sharing rule. The optimal sharing rule must maximize the firm's overall payoff (which is the joint payoff of the partners), subject to the partners' participation constraint that each partner must earn at least his reservation wage from the partnership. Without loss of generality, the reservation wage is assumed to be zero. ${ }^{20}$

For tractability of analysis, we consider only linear sharing rules. ${ }^{21}$ Specifically, a partner's compensation is held to be a linear function of various contractible performance measures, including audit fee revenues, consulting fee revenues, and legal liability costs. As clients are identical, we focus on the sharing

\footnotetext{
${ }^{19}$ In practice, the magnitude of $l$ depends on many institutional factors, such as the incorporated wealth of the audit firm and the strength of the legal regime.

${ }^{20}$ The optimal sharing rule must maximize the payoff for the partnership as a whole. To understand this, suppose that Rule X yields a higher firm payoff than Rule Y, but that the audit partner prefers Rule X and the consulting partner prefers Rule Y. Then, there is always an ex ante lump-sum transfer from the audit partner to the consulting partner, so that the consulting partner has no preference between Rule X and Rule $\mathrm{Y}$ and the audit partner still prefers Rule $\mathrm{X}$. The ex ante lump-sum transfer has no incentive effects, i.e., it does not affect the production decisions of the partners and thus does not affect the firm's overall payoff.

${ }^{21}$ As Coase (1937) suggested, a firm may not be able to write a contract based on all verifiable events because of the prohibitively high transaction costs involved in enforcing such a contract. This may explain why, in practice, firms use simple linear compensation schemes. In fact, many compensation formulas used in audit firms can be translated to linear sharing rules (see Liu 2002). For example, as shown in Section 4.1, the sharing rule that bases a partner's compensation on the overall profit of the firm with variable incentive weights (partnership "units") may be translated to a linear sharing rule with fixed incentive weights.
} 
of the revenues and costs from a representative client. The partners' compensation from a client engagement is described as follows.

$y^{a}=\alpha f^{a}+\beta \lambda^{c} f^{c}-\gamma \lambda^{l} l$,

$y^{c}=(1-\alpha) f^{a}+(1-\beta) \lambda^{c} f^{c}-(1-\gamma) \lambda^{l} l$,

where

$y^{a}: \quad$ the audit partner's compensation,

$y^{c}$ : the consulting partner's compensation,

$f^{a}:$ the audit fee,

$f^{c}$ : the consulting fee,

$l$ : the legal liability cost,

$\alpha: \quad$ the audit partner's share of the audit fee,

$\beta: \quad$ the audit partner's share of the consulting fee,

$\gamma: \quad$ the audit partner's share of the legal liability cost,

$\lambda^{c}: \quad$ an indicator variable that equals one if a consulting task is obtained and zero otherwise, and

$\lambda^{l}: \quad$ an indicator variable that equals one if auditor litigation occurs and zero otherwise.

In this sharing rule specification, the incentive weights $\alpha, \beta$, and $\gamma$ determine how the partners share the audit fee, consulting fee, and legal liability cost, respectively. Consistent with the common practice in the audit industry, the sharing rule is not observable to outsiders, including clients (shareholders) and other audit or consulting firms. ${ }^{22}$

${ }^{22}$ This is a realistic assumption as an audit partnership is a private firm and little is known about 
The main objective of this study is to examine the effects of the SEC (2003) regulation that prohibits audit partners from receiving compensation based on the sale of non-audit services to the companies that they audit. This implies that in our model, the incentive weight of $\beta$ is unrestricted prior to the SEC regulation, but is restricted to zero in the post-regulation period.

\subsection{Sequence of Events}

The events in the one-period model can be summarized as follows. At Stage 0 , the audit partner and the consulting partner in each firm decide on their sharing rule. ${ }^{23}$ A partner will not participate in the game if his expected payoff is less than the reservation payoff of zero. At Stage 1, the audit partners from the two firms submit bids to the shareholders in competition for audit engagements. The audit fee $f^{a}$ is determined by competition. At Stage 2, each audit partner expends effort for each audit engagement obtained. At Stage 3, for each company, a consulting task (if it exists) becomes known to the audit partner. At Stage 4, each company's auditor issues an audit opinion. At Stage 5, the shareholders decide whether to invest in or liquidate a company depending on the audit opinion. Given the assumption that $p R>I>\varphi R+\pi$, we know that the shareholders will invest in a company with an unqualified opinion and liquidate a company with a qualified opinion. The game for a company ends here if the shareholders liquidate the company, but proceeds to the next stage if they decide to invest in it. At Stage 6 , if a consulting task exists, then the shareholders choose between the consulting partner of the audit firm and an outside consultant to perform the consulting task. The consulting fee $f^{\mathfrak{c}}$ is also determined by competition. Finally, the cash flow of

the details of the partnership sharing rule. If the sharing rule were observable to the general public, then the firm would choose the sharing rule that induces the partner actions that maximize the welfare of the economy (i.e., the joint payoffs to shareholders and the audit firm), rather than maximizing the firm's payoff. In that case, auditor independence would not be an issue.

${ }^{23}$ We do not allow sharing rule renegotiation after Stage 0 since auditor effort is not observable or contractible. 
each company is realized, and legal payments are made from the audit firm to the shareholders if the company fails. Partners of each firm are then compensated according to the sharing rule that was established at the beginning of the game. The model structure is common knowledge. The stages of the game are illustrated in Figure 1 for easy reference.

\section{[Insert Figure 1 Here.]}

\subsection{Equilibrium Concept}

As the firm's sharing rule is not observable to people outside the firm, the game is a dynamic game with imperfect information. We solve the game for a perfect Bayesian equilibrium with pure strategies (see Tirole 2002, 438, for the definition of the equilibrium). Note that the partners of each firm compete with different players at different stages of the game. The audit partner competes with the rival audit partner when bidding for an audit task at Stage 1, and the consulting partner competes with a rival consultant when bidding for a consulting task at Stage 6. The following assumptions are made regarding the bidding strategies. First, as in Grossman (1981) and Hurter and Lederer (1986), "incredible threats" are eliminated by assuming that a player will not bid a price that is below his break-even price. Second, prices are restricted to non-negative values. Third, to avoid dealing with $\varepsilon$-equilibrium (see Tirole 2002, 234), the following technical assumption is made in the case of a tie in price. When two players bid the same price for a task, the player with the lower break-even price wins the bid; when their break-even prices are the same, the player with the lower production cost wins the bid; and when both their break-even prices and production costs are the same, the two players have an equal chance of winning the bid. 


\section{Analysis}

\subsection{Optimal Partner Decisions before the Regulatory Change}

In this section we assume that all partners always act in the interest of their firm as a whole, and derive the optimal partner decisions for the firm. Under this assumption, the partners choose actions to maximize the firm's overall payoff, which is the sum of the payoffs of the individual partners of the firm. Of course, the partners will not make optimal decisions without a proper incentive structure. The incentive structure considered in this study is the firm's sharing rule. The discussion of the optimal sharing rule is deferred until the next section.

When a consulting task arises for an audit client, given that $r>v$, and the assumed tie-breaking rule, the consulting partner of the audit firm will submit his best offer, $r$, and win the bid for the consulting task. Hence, the firm's payoff from a consulting task is $(r-v)$, which equals the cost advantage enjoyed by the consulting partner over an outside consultant. Suppose that $r-v \leq(1-\varphi) l$, i.e., the future payoff from consulting, $(r-v)$, is less than the expected legal liability cost of an audit failure, $(1-\varphi) l$, then acting in the best interest of the firm, the audit partner reports truthfully. ${ }^{24}$ Thus, in this case the issue of auditor independence is mute. The focus of our analysis is on the other more interesting case, where

$$
r-v>(1-\varphi) l .^{25}
$$

\footnotetext{
${ }^{24}$ We assume that when indifferent between reporting policies, the auditor will report truthfully.

${ }^{25} r$ is large. Consulting services have grown rapidly in the accounting profession since the mid1970s, and by 2000, the Big Five audit firms had expanded into multidisciplinary service firms that earned more than half of their gross fees from non-audit services. See Zeff (2003) and Wyatt (2003) for a historical review of the development of non-audit services in the accounting profession and their effect on auditor independence.
} 
We will maintain this assumption in the following analysis. ${ }^{26}$ In this case, when a consulting task arises and the audit partner finds evidence of misstatements, the payoff to the firm of issuing an unqualified opinion is $r-v-(1-\varphi) l>0$, and that of issuing a qualified opinion is zero. Hence, from the firm's point of view, the audit partner should suppress evidence of misstatements and issue an unqualified opinion in the presence of a lucrative consulting task. Given this reporting strategy, Figure 2 depicts the game tree for the effort choice problem.

\section{[Insert Figure 2 here.]}

The optimal audit effort minimizes the firm's cost of the audit, denoted by $C$ :

$$
\operatorname{Min}_{e \in[0,1]} C=k e^{2}+(1-p)[(1-e)+e \theta](1-\varphi) l-\theta(r-v) .
$$

From (3), the cost of the audit is equal to the audit effort cost, plus the expected legal liability cost, minus the expected consulting profit. To ensure an interior solution for the effort, i.e., $e^{*} \in(0,1)$, we assume $k>(1-p)(1-\theta)(1-\varphi) l / 2$. Solving the first-order condition for (3) yields the optimal audit effort:

$$
e_{1}^{*}=\frac{(1-p)(1-\theta)(1-\varphi) l}{2 k}
$$

where the subscript 1 refers to the solution before the regulatory change. ${ }^{27}$ As expected, the optimal audit effort, $e_{1}^{*}$, increases with the expected legal liability,

\footnotetext{
${ }^{26}$ Our unreported analysis finds that in the opposite case where $r-v \leq(1-\varphi) l$, while the SEC regulation (2003) on auditor compensation changes the firm's sharing rule, it has no effect on partner behavior.

${ }^{27}$ The second-order condition is satisfied because $k>0$.
} 
$(1-\varphi) l$, or the probability of the manager's misreporting, $(1-p)$, but decreases with the effort cost parameter, $k$, or the probability of the existence of a consulting task, $\theta$. However, with an opportunistic audit reporting strategy, audit effort is not a function of the consulting profit, $(r-v)$, as long as $(r-v)$ is greater than $(1-\varphi) l$.

\subsection{Optimal Sharing Rule before the Regulatory Change}

The previous section shows the optimal partner decisions for the firm. However, partners make decisions to maximize their personal payoffs, not necessarily the payoff of the firm as a whole. Indeed, at the start of the game the partners have to negotiate and agree on a sharing rule to induce the firm's desired partner behavior. Lemma 1 below characterizes the sharing rule that induces the optimal partner decisions for an audit engagement that has been obtained.

Lemma 1: Given that an audit firm is engaged to perform an audit for a given fee, the unique values of $\beta$ and $\gamma$ are characterized by $\beta_{1}^{*}=(r-v) / r$ and $\gamma_{1}^{*}=1$, respectively, such that the partners of the firm are induced to make decisions to maximize the firm's payoff (minimize the firm's cost) for the audit for any given values of $r, v$, and $(1-\varphi) l$.

Lemma 1 shows that a simple sharing rule that comprises $\beta_{1}^{*}=(r-v) / r$ and $\gamma_{1}^{*}=1$ motivates the partners to choose the firm's desired actions. To see how this simple sharing rule works, let us first consider the consulting partner's bidding strategy when a consulting task arises. Given $\left\{\beta_{1}^{*}, \gamma_{1}^{*}\right\}$, the consulting partner's break-even price for the consulting task is $v /\left(1-\beta_{1}^{*}\right)=r$, the same as the firm's break-even price. As a result, the consulting partner will win the bid with the price of $r$ and the firm's consulting payoff achieves a maximum of $(r-v)$ in 
competition.

Next, let us move one step back to consider the auditor's reporting decision. Given any audit evidence, the sharing rule $\left\{\beta_{1}^{*}, \gamma_{1}^{*}\right\}$ equates the audit partner's personal payoff with the firm's payoff, i.e., $\beta_{1}^{*} r-\gamma_{1}^{*}(1-\varphi) l=r-v-$ $(1-\varphi) l$. Accordingly, the audit partner is induced to adopt the optimal reporting strategy for the firm. Specifically, when the audit partner finds evidence of misstatements, he issues an unqualified opinion if a consulting task exists (as $\left.\beta_{1}^{*} r>\gamma_{1}^{*}(1-\varphi) l\right)$, and issues a qualified opinion otherwise.

Finally, let us move one further step back to see how the sharing rule $\left\{\beta_{1}^{*}, \gamma_{1}^{*}\right\}$ induces the audit partner to expend the optimal level of effort for the firm in the performance of an audit. In contrast to the firm's objective function (3), the audit partner's objective is to choose the level of effort that minimizes his own personal cost, which is denoted by $c$ :

$$
\underset{e \in[0,1]}{\operatorname{Min}} c=k e^{2}+(1-p)[(1-e)+e \theta] \gamma(1-\varphi) l-\theta \beta r
$$

Comparing (3) with (5), we see that when $\beta_{1}^{*}=(r-v) / r$ and $\gamma_{1}^{*}=1$, the objective functions of the audit partner and the firm coincide. This implies that the audit partner will expend the optimal level of effort from the firm's point of view.

Before equilibrium is derived, let us consider how the shareholders choose an auditor. As the firm's sharing rule is not observable to outsiders, the shareholders choose an auditor based on the observed audit fee and their conjecture about the firm's sharing rule. Note that for any given audit fee, the optimal sharing rule for the firm is the one that induces the partners to choose actions that minimize the firm's audit cost. In the belief that the firm uses the costminimizing sharing rule, the shareholders expect to obtain a fixed amount of gross 
benefit (before the audit fee) that is determined by the induced partners' actions. ${ }^{28}$ Thus, the shareholders hire the least costly auditor for the fixed benefit, i.e., the auditor that has submitted the lowest audit bid. This reasoning indicates that when the firm's sharing rule is unobservable to the shareholders, the auditor cannot use different audit fees to creditably signal differing audit quality (i.e., a differing assurance level that the financial report is free of misstatements). Given that the shareholders will choose the auditor that bids the lowest audit fee, Proposition 1 characterizes a perfect Bayesian equilibrium.

Proposition 1: The following constitutes a perfect Bayesian equilibrium.

(a) Each firm uses a dominant sharing rule against the rival firm. In particular, each firm has a unique sharing rule that is characterized by $\alpha_{1}^{*}=1$, $\beta_{1}^{*}=(r-v) / r$, and $\gamma_{1}^{*}=1$ that is a dominant compensation strategy against the rival firm for any given values of $r, v$, and $(1-\varphi) l$.

(b) The shareholders choose the auditor who bids the lowest audit fee, and have no preference between auditors if they bid the same fee.

(c) For any observed audit fee (including an off-the-equilibrium fee), the shareholders believe that the firm uses a sharing rule that minimizes the firm's audit cost.

In equilibrium, each firm bids the audit fee of $f_{1}^{a^{*}}=C\left(\beta_{1}^{*}, \gamma_{1}^{*}\right)$, has an equal expected share of the audit market $E\left[n_{i}\right]=n / 2$, where $i \in\{A, B\}$, and performs consulting tasks for its audit clients for the consulting fee of $f_{1}^{c *}=r$.

The intuition for the optimality of the sharing rule $\left\{\alpha_{1}^{*}, \beta_{1}^{*}, \gamma_{1}^{*}\right\}$, as

\footnotetext{
${ }^{28}$ The gross benefit of an audit equals the expected savings of the wasteful investment in a company with a misstated report, plus the expected legal payment that is received from the audit firm.
} 
characterized in Proposition 1, is straightforward. We know from the explanation of Lemma 1 that the sharing rule $\left(\beta_{1}^{*}, \gamma_{1}^{*}\right)$ motivates the partners to make decisions to minimize the firm's audit cost during Stages 2-6. Furthermore, given $\left\{\alpha_{1}^{*}, \beta_{1}^{*}, \gamma_{1}^{*}\right\}$, the audit partner's break-even price for an audit engagement equals the firm's cost, i.e., $c\left(\beta_{1}^{*}, \gamma_{1}^{*}\right) / \alpha_{1}^{*}=C\left(\beta_{1}^{*}, \gamma_{1}^{*}\right)$. Accordingly, the audit partner's bidding strategy at Stage 1 is also optimal from the firm's point of view. In sum, the sharing rule $\left\{\alpha_{1}^{*}, \beta_{1}^{*}, \gamma_{1}^{*}\right\}$ is optimal because it induces the partners to make decisions to maximize the firm's overall payoff by aligning the partners' personal payoffs with the firm's payoff during Stages 1-6 of the game.

It is noteworthy that the firm's cost minimization through the choice of $\left\{\alpha_{1}^{*}, \beta_{1}^{*}, \gamma_{1}^{*}\right\}$ ensures that the audit partner can submit the most competitive (winning) audit bid, and that no one partner could demand a change in the sharing rule and be better off. For example, if the consulting partner wanted an increase in his share of the consulting fee (i.e., a decrease in $\beta$ ), then the audit partner would not win the competition for an audit as his personal cost in (5) (and also his breakeven price) would increase. As a consequence, the consulting partner would lose the bid for the consulting contract.

In equilibrium, the audit fee equals the firm's cost of an audit and is given by

$$
f_{1}^{a *}=C\left(\beta_{1}^{*}, \gamma_{1}^{*}\right)=k e_{1}^{* 2}+(1-p)\left[\left(1-e_{1}^{*}\right)+e_{1}^{*} \theta\right](1-\varphi) l-\theta(r-v) .
$$

The equilibrium audit fee decreases with the consulting payoff $(r-v)$, which is consistent with actual observations. For instance, a former Arthur Young audit partner, Mr. Chapin, stated "we have been told that some companies are offering audits - their exclusive franchise - at big discounts to attract clients for their more 
lucrative consulting services. Some say the profession's traditional function has been downgraded to a loss leader" (CPA Journal 1992).

In equilibrium, the audit partner's expected payoff from a client is zero as the equilibrium audit fee is equal to the audit partner's break-even price. Specifically, the expected payoff of the audit partner from a client is

$$
\alpha_{1}^{*} f_{1}^{a *}+\theta \beta_{1}^{*} f_{1}^{c *}-(1-p) \gamma_{1}^{*}(1-\varphi) l-k e_{1}^{* 2}=0 .
$$

The consulting partner's expected payoff from a client is also zero:

$$
\left(1-\alpha_{1}^{*}\right) f_{1}^{a *}+\theta\left[\left(1-\beta_{1}^{*}\right) f_{1}^{c *}-v\right]-(1-p)\left(1-\gamma_{1}^{*}\right)(1-\varphi) l=0 .
$$

It is also noteworthy that in equilibrium the audit partner shares the consulting revenue (i.e., $\beta_{1}^{*}>0$ ), even though the consulting task is solely performed by the consulting partner. This result follows from the fact that it is in the firm's best interest to suppress any evidence of misstatements and issue an unqualified opinion in the presence of a lucrative consulting task. If the audit partner does not share the consulting revenue, then his personal payoff will not incorporate the potential consulting profit. Therefore, the audit partner's actions will be incompatible with the firm's interests. Specifically, if $\beta_{1}^{*}=0$, the audit partner will report any evidence of misstatements despite the existence of a large consulting profit, and the audit partner's effort choice will be sub-optimal from the firm's point of view. In contrast, $\beta_{1}^{*}=(r-v) / r$ helps to align the audit partner's personal payoff with the firm's payoff, thereby inducing the audit partner to make the optimal effort and reporting decisions for the partnership as a whole. 
The above analysis shows that when the future consulting payoff is relatively large, i.e., $r-v>(1-\varphi) l$, the optimal sharing rule induces the audit partner to suppress evidence of misstatements to pursue large consulting profits. ${ }^{29}$ This possibility of untruthful reporting provides the rationale for the government to intervene in the compensation structure of audit firms.

The reason behind the audit firm's lack of independence is that future consulting opportunities for audit firms depend on audit reports. Magee and Tseng (1990, Propositions 1-4) show that the auditor's quasi-rent from audit tasks does not generally lead to a compromise in auditor independence. ${ }^{30}$ Our model and analysis differ from Magee and Tseng (1990) in the assumption about whether auditors' future contracts are contingent on audit reports. In their setting, clients cannot offer report-contingent audit contracts to auditors. The client cannot commit to firing an auditor who provides an unfavorable audit report. Such a threat is incredible because it is optimal for the client to continue with the incumbent auditor after the audit report is issued, when the incumbent auditor can bid a lower audit fee than external auditors. In our setting, auditors' future consulting opportunities will depend on their audit reports. A company (project) is not worth continued operation (investment) when a qualified audit report is issued, hence any potential consulting profits will be lost if the audit report is unfavorable. This seeks to capture the situation where clients have some control over the

\footnotetext{
${ }^{29}$ This result is consistent with the observation that although Arthur Andersen knew that the audit team had been given a low evaluation - 2 marks out of a total of 5 - for the audit work for Enron, the headquarters of Arthur Andersen did not take any action to "rock the boat" (see the indictment by the U.S. government against Arthur Andersen at http://news.findlaw.com/hdocs/docs/enron/usandersen030702ind.html).

${ }^{30}$ If the lack of auditor independence is due to the auditor's fear of losing the audit contract/profit, and the consulting profit alone does not lead to the auditor' untruthful reports, then the SEC regulation would have no impact on auditor behavior, because it did not address the root cause of the problem. Our results would not be qualitatively affected if the lack of auditor independence is due to both the audit and consulting profits, but the audit profit alone is not sufficiently large to cause the auditor to issue false reports.
} 
"existence" of consulting opportunities. In reality, the clients' management normally has private information about whether and where consulting services are needed to improve the operations of the business and can thus use such consulting opportunities as "bribes" to auditors.

\subsection{Government Intervention in the Compensation Structure of Audit Firms}

To help restore auditor independence, the SEC issued a regulation related to auditor compensation in 2003 (SEC 2003, Section 2E). Under this regulation, an audit partner is deemed not to be independent from the companies he audits if he is also receiving compensation from the sale of non-audit services to the same companies. Thus, the regulation demands that an audit partner's compensation not be based on the sale of non-audit services to these companies. Following the spirit of this regulation implies that, in our model, the audit partner's incentive weight for the consulting revenue, $\beta$, is restricted to zero. We now examine the effects of this regulation on the partners' decisions and the welfare of the economy.

It is noteworthy that SOX (Section 201) and the SEC (2003) rule (Section 2B) prohibit auditors from providing their audit clients with nine categories of non-audit services, including, for example, bookkeeping and internal audit control outsourcing services. Auditors are still allowed to provide other services that are regarded as not directly producing financial statement numbers, such as tax consulting and general management consulting services. New consulting opportunities for audit firms arise in the post-SOX period, which help client companies to comply with internal control reviews and more complex disclosure requirements imposed by SOX. Thus, $r$ in (2) remains large in the post-regulation period. To isolate and focus on the effects of the SEC regulation of auditor compensation, in the main analysis we make a comparison between the pre- and post-regulation situations under the assumption that the scope of non-audit services remains the same after the regulation. Later in Section 4.4, we discuss 
how the analytical results of the model will be affected if we also consider the SEC's restriction on the scope of non-audit services.

Proposition 2 characterizes a perfect Bayesian equilibrium after the regulatory change, which is denoted by the subscript 2 . To ensure that $e_{2}^{*} \in(0,1)$, we assume $(1-\varphi) l>\theta(r-v)$.

Proposition 2: Under the regulation that requires $\beta=0$, a perfect Bayesian equilibrium is characterized as follows.

(a) Each audit firm uses a dominant sharing rule against the rival firm. In particular, each firm has a unique sharing rule that is characterized by $\alpha_{2}^{*}=\frac{C\left(\beta_{2}^{*}, \gamma_{2}^{*}\right)+p \theta(r-v)}{C\left(\beta_{2}^{*}, \gamma_{2}^{*}\right)}>1, \beta_{2}^{*}=0$, and $\gamma_{2}^{*}=\frac{(1-\varphi) l-\theta(r-v)}{(1-\varphi) l} \in(0,1)$ that is a dominant compensation strategy against the rival firm for any given values of $r, v$, and $(1-\varphi) l$. The optimal auditor choice and posterior beliefs of shareholders are the same as those in Parts (b) and (c) of Proposition 1. In equilibrium, each firm bids the audit fee of $f_{2}^{a *}=C\left(\beta_{2}^{*}, \gamma_{2}^{*}\right)$, has an equal expected share of the audit market $E\left[n_{i}\right]=n / 2$ where $i \in\{A, B\}$, and performs consulting tasks for its audit clients for the consulting fee of $f_{2}^{c *}=r$.

(b) The audit partner reports truthfully, yet adopts a level of audit effort that is lower than that before the regulation, i.e., $e_{2}^{*}=(1-p)[(1-\varphi) l-\theta(r-v)] / 2 k<e_{1}^{*}$.

Proposition 2 shows that the partners of each audit firm will react to the regulation strategically by changing the firm's optimal sharing rule. As the audit partner is not allowed to receive variable pay based on consulting revenue, namely, $\beta_{2}^{*}=0$, the audit partner will issue a qualified opinion when he detects material misstatements. This means that the regulation restores truthful reporting. 
If the firm's liability-sharing rule remains unchanged, one might expect the audit partner to work harder because any advantages (i.e., consulting profits) of not finding and reporting evidence of misstatements are gone, and hence the welfare will improve after the regulation. However, our analysis reveals that the partners strategically change the firm's liability-sharing rule such that the audit partner will actually expend less effort after the regulation $\left(e_{2}^{*}<e_{1}^{*}\right)$.

The reason for the change of the liability-sharing rule and the reduced audit effort is as follows. Before the regulation, the audit partner suppressed evidence of misstatements for the companies for which the audit firm also supplied consulting, and thus also received the consulting profit from these companies. After the regulation, the audit partner issues a qualified opinion for any company in which he finds evidence of misstatements, regardless of the existence of a consulting task. This causes the firm to forgo the consulting profit from the companies in which the audit partner detects financial misstatements. In response, the partners optimally change to a sharing rule that induces a lower level of audit effort to pursue consulting profits that could be forgone if the effort level were the same as before the regulation. More specifically, the optimal liability-sharing rule reduces the portion of legal liability that the audit partner must bear $\left(\gamma_{2}^{*}<1\right)$, and thus the audit partner has less incentive to work hard. The idea behind the reduced effort is that the audit partner's personal benefit from putting in effort to avoid an audit failure decreases if his share of the legal liability cost decreases (while his consulting partner pays a higher "tax"), therefore the audit partner will optimally choose a lower level of audit effort. The audit effort becomes $e_{2}^{*}=(1-p)[(1-\varphi) l-\theta(r-v)] / 2 k$, which is lower than $e_{1}^{*}=(1-p)(1-\theta)(1-\varphi) l / 2 k$ prior to the regulation.

The new audit-fee-revenue sharing rule is greater than one, i.e., 
$\alpha_{2}^{*}=\left[C\left(\beta_{2}^{*}, \gamma_{2}^{*}\right)+p \theta(r-v)\right] / C\left(\beta_{2}^{*}, \gamma_{2}^{*}\right)>1$. The reason is as follows. The firm's audit cost incorporates the (minus) expected consulting profit; however, the audit partner's personal cost does not as he does not share the consulting revenue. As a result, the audit partner's personal cost of the audit is greater than the firm's cost. ${ }^{31}$ Therefore, to align the audit partner's break-even price with the firm's cost, a larger incentive weight for audit fee revenue is given to the audit partner (i.e., $\alpha_{2}^{*}>\alpha_{1}^{*}=1$ ). As a consequence, the audit partner is induced to bid aggressively below his personal cost in the interests of the partnership as a whole.

In equilibrium, the audit partner's expected payoff from a client is zero, as the equilibrium audit fee equals the audit partner's break-even price. Specifically, the expected payoff of the audit partner from a client is

$$
\alpha_{2}^{*} f_{2}^{a *}+\left[p+(1-p)\left(1-e_{2}^{*}\right)\right] \theta \beta_{2}^{*} f_{2}^{c *}-(1-p)\left(1-e_{2}^{*}\right) \gamma_{2}^{*}(1-\varphi) l-k e_{2}^{* 2}=0
$$

The consulting partner's expected payoff from a client is also zero:

$$
\begin{aligned}
& \left(1-\alpha_{2}^{*}\right) f_{2}^{a^{*}}+\left[p+(1-p)\left(1-e_{2}^{*}\right)\right] \theta\left[\left(1-\beta_{2}^{*}\right) f_{2}^{c^{*}}-v\right] \\
& -(1-p)\left(1-e_{2}^{*}\right)\left(1-\gamma_{2}^{*}\right)(1-\varphi) l=0 .
\end{aligned}
$$

The consulting profit $(r-v)$ that is earned by the consulting partner is transferred to the audit partner through the sharing of the legal liability $\operatorname{cost}\left(\gamma_{2}^{*}<1\right)$ and the audit fee $\left(\alpha_{2}^{*}>1\right)$. The profit is then transferred to clients through competitive bidding for the audit tasks.

\footnotetext{
${ }^{31}$ As is shown in the proof of Proposition 2, $C\left(\beta_{2}^{*}, \gamma_{2}^{*}\right)=c\left(\beta_{2}^{*}, \gamma_{2}^{*}\right)-p \theta(r-v)$, where $C\left(\beta_{2}^{*}, \gamma_{2}^{*}\right)$ is the firm's cost of an audit, $c\left(\beta_{2}^{*}, \gamma_{2}^{*}\right)$ is the audit partner's personal cost, and $p \theta(r-v)$ is the consulting profit that can be expected from a company that has issued a correctly stated financial report.
} 
Thus far, we have not introduced any welfare implications for the change of regulation. To allow welfare comparisons, we define the welfare of each client and audit firm pair as the sum of the expected payoffs of the shareholders of the company and the audit firm. Because the expected payoff of the audit firm is zero, the welfare equals the shareholders' expected payoff. As expected, both the audit partner's reporting and effort decisions come into play in determining the welfare effect of the SEC (2003) regulation of auditor compensation, which is shown in Proposition 3.

Proposition 3: The regulation improves the welfare of each client and audit firm pair if $l \geq \frac{(r-v) \sigma_{2}}{(1-\varphi)\left[(1-\theta) \sigma_{1}+\sigma_{2}\right]}$, where $\sigma_{1} \equiv I-\varphi R-(\pi-v)$ and $\sigma_{2} \equiv I-\varphi R-\theta(\pi-v)$.

As shown in Proposition 2, the optimal sharing rule and the audit partner's effort and reporting decisions change in response to the regulation. On the one hand, the regulation restores truthful reporting, which helps to improve the investment decisions of shareholders and thus enhances welfare. On the other hand, the audit partner's effort decreases, which has a negative effect on welfare. Whether the regulation improves welfare depends on which of these two effects dominates.

Proposition 3 shows that the regulation improves welfare if the legal liability cost of auditor litigation is sufficiently large, i.e., $l \geq \frac{(r-v) \sigma_{2}}{(1-\varphi)\left[(1-\theta) \sigma_{1}+\sigma_{2}\right]}$. The reason is as follows. When the legal liability cost is sufficiently large, the effortreducing effect of the regulation becomes the secondary factor. ${ }^{32}$ As a result, the welfare loss due to the reduced effort is outweighed by the welfare gain that is afforded by truthful reporting, which leads to an overall improvement in welfare.

\footnotetext{
${ }^{32}$ Note that $e_{1}^{*}-e_{2}^{*}=(1-p) \theta[r-v-(1-\varphi) l] / 2 k$ decreases with $l$.
} 
When the legal liability cost is small, however, the regulation can result in a lower level of welfare, as the effort-reducing effect of the regulation can be the dominant factor.

In summary, although the regulation of audit compensation restores truthful reporting, it has an unintended negative effect on audit effort. The welfare effect of the regulation depends on the strength of the legal regime (as characterized by the magnitude of the expected legal liability $l$ ). In a strong (weak) legal regime where the truthful-reporting effect (the effort-decreasing effect) is likely to be the dominant factor, the regulation can lead to an overall increase (decrease) in welfare.

To gain further insights into the condition in Proposition 3, i.e., $l \geq \frac{(r-v) \sigma_{2}}{(1-\varphi)\left[(1-\theta) \sigma_{1}+\sigma_{2}\right]}$. We note that $\sigma_{2} \equiv I-\varphi R-\theta(\pi-v)$ represents the expected shareholder loss from an audit failure. If the legal regime is characterized by the out-of-pocket liability/damage measure, the expected legal liability from an audit failure will be set to equal the expected shareholder loss from the audit failure, i.e., $(1-\varphi) l=\sigma_{2}$, which means $l=\frac{\sigma_{2}}{1-\varphi}$. If this is the case, then it can be shown that a sufficient condition for the inequality $l \geq \frac{(r-v) \sigma_{2}}{(1-\varphi)\left[(1-\theta) \sigma_{1}+\sigma_{2}\right]}$ to hold is that $\sigma_{2}>r-v$. In other words, under the out-of-pocket liability/damage regime where $l$ is as large as $\frac{\sigma_{2}}{1-\varphi}$, the SEC regulation (2003) will improve the welfare of the economy when the expected shareholder loss from an audit failure, $\sigma_{2}$, exceeds the audit firm's rent from consulting services, $r-v$.

\section{Further Discussions}

\subsection{Sharing in the Overall Profit Pool and the Effectiveness of the Regulation}

Our model assumes a linear sharing rule. In practice, a partner's compensation is sometimes a proportionate share of the firm's overall profits, 
which include profits from audit and non-audit services. A partner's share in the overall profits is often labeled as "units", which can vary based on the evaluation of the performance of the partner. However, suppose we set the partner's units to be $y^{i} /$ (overall firm profit), $i=\mathrm{a}$, c, where $y^{i}$ is the partner's compensation as defined in Section 2.3, then it is easy to see that the units-based sharing rule is actually equivalent to the linear sharing rule as specified in Section 2.3. In other words, when the partners share in the overall profit of the firm, the firm can choose an appropriate incentive weight (i.e., performance varying "units") such that a partner's compensation can vary with the audit fee, the consulting fee, and the legal liability cost in the same way that is dictated by the linear sharing rule.

As explained in the Introduction, the SEC compensation rule (2003, Section 2E) contains a modifier that neither precludes an audit partner from sharing in the profit pool of the overall firm, nor precludes the audit firm from evaluating an audit partner based on factors related to the sale of non-audit services. The above analysis shows that allowing the partner's share in the firm's overall profits to vary with consulting revenues would have a similar effect on partner compensation to allowing the incentive weight of $\beta$ in a linear sharing rule to be non-zero. Therefore, this modifier to the rule may allow an audit partner's compensation to be based on the consulting revenues to circumvent the intended goal of the regulation, causing the same independence problem as before the regulation.

Hence, the effectiveness of the SEC rule hinges on the ability of the regulatory body to ensure that the audit partner's compensation does not vary with the consulting revenues. This requires prohibiting audit partners from directly sharing the consulting revenues from their audit clients, or their performance pay from indirectly depending on selling consulting services to their audit clients. ${ }^{33}$

\footnotetext{
${ }^{33}$ In the comment letter addressed to the SEC in January 2003, the former SEC chief accountant Lynn Turner expressed the similar view that audit partners should not be evaluated based on the
} 


\subsection{Economies of Scope in Audit Firms}

In this study, the economies of scope in the joint provision of audit and non-audit services by the audit firm are that the client knowledge documented by the audit partner can be shared with the consulting partner. Thus, the consulting partner enjoys a competitive cost advantage over an outside consultant in performing a consulting task. The output of consulting services, such as tax returns, accounting policy consultation, and various assessments and advice, is assumed to be contractible. In other words, there are no motivational issues with respect to the consulting partner's tasks (except his bidding behavior). This is consistent with the SEC's view on the economies of scope in audit firms (see SEC 2003, Section 4C-1a) and that the consulting arm of the audit firm is largely a source of revenues for the audit firm when establishing the SEC's 2003 rules. In this context, the "moral hazard problem" between the partners in the audit firm is resolved by the optimal sharing rule that they contract on at the start of the game.

We have tried alternative models in which more complex cooperation in production is required between the partners of the firm, such that there is no sharing rule that perfectly aligns the partners' payoffs with the firm's payoff to resolve the firm's moral hazard problem. We find that the model and analysis become more complex and entail simulation and numerical analysis. However, our results regarding the change in the liability-sharing rule and the auditor's effort may not change as shown in the following example.

Example 1: In our model, we make an additional assumption that the consulting partner also participates in the audit. That is, the consulting partner's expertise and effort, denoted by $a$, can help the audit partner in the performance of the audit task. In particular, we assume that the probability of finding evidence of

success in selling non-audit services to their audit clients (see
http://sec.gov/rules/proposed/s74902/lturner1.htm). 
misstatements in a misstated financial report is $(e+e a)$. The marginal cost of the audit partner's (consulting partner's) audit effort is $k_{1}\left(k_{2}\right)$. The simulation of the analysis uses the following arbitrary parameter values: $p=0.5, \varphi=0.05, \theta=0.2, l$ $=3.16, I=9, R=20, \pi=7, r=6, v=1, k_{1}=2$, and $k_{2}=4$. It can be shown that the optimal sharing rules before and after the regulation are $\left\{\beta_{1}{ }^{*}=0.48, \gamma_{1}{ }^{*}=\right.$ $0.96\}$ and $\left\{\beta_{2}{ }^{*}=0, \gamma_{2}{ }^{*}=0.586\right\}$, respectively. The effort choices before and after the regulation are $\left\{e_{1}{ }^{*}=0.2885, a_{1}{ }^{*}=0.0017\right\}$ and $\left\{e_{2}{ }^{*}=0.2199, a_{2}{ }^{*}=0.0006\right\}$, respectively.

In the above example, while the optimal sharing rule does not perfectly align the partners' payoffs with the firm's payoff for the audit efforts $a$ and $e$, the liability-sharing rule $\gamma$ is reduced to induce less audit effort after the regulation. This is consistent with our results in Section 3.

\subsection{Alternative Regulatory Interventions to Restore Truthful Reporting}

The current model focuses on the SEC (2003) regulation related to auditor compensation and does not consider alternative regulatory intervention to restore truthful reporting. For example, the government could prohibit audit firms from performing any consulting services at all for the companies that they audit. It can be shown that, under such a regulation, auditors will report truthfully and their effort levels will become higher than when consulting services are allowed, as audit firms have no incentive to hold back audit efforts when consulting profits are gone and the audit service becomes the sole product. However, such a regulation would eliminate the audit firm's economies of scope in the joint provision of audit and consulting services. Therefore, whether the shareholders would be better off depends on the tradeoff between the benefit gained from 
truthful reporting and the lost economies of scope for non-audit services. ${ }^{34}$

\subsection{Joint Consideration of the SOX Restriction (2003) on the Scope of Non- Audit Services}

Data from Audit Analytics show that the average ratios of non-audit fee to total fee for publicly traded companies are $0.42,0.39$, and 0.29 for the pre-SOX years of 2000, 2001, and 2003, respectively. In contrast, the average ratios of nonaudit fee to total fee are reduced to $0.15,0.14$, and 0.14 for the post-SOX years of 2007,2008 , and 2009, respectively. This reduction in non-audit fee ratio is mainly caused by the restriction on the scope of non-audit services imposed by SOX (Section 201) and the SEC (2003) rule (Section 2B). Here, we discuss how the analytical results of the current model are affected if we also consider the SEC's restriction on the scope of non-audit services.

There are two possible situations. First, the scope of the non-audit service is reduced to such an extent that the new consulting rent becomes less than the expected loss of an audit failure in the post-SOX period. In this case, the auditor will report truthfully and his effort level also becomes higher in the post-SOX period, because the expected consulting rent for the audit firm is insignificant compared with the expected litigation cost. This has a positive effect on the welfare of the economy. However, there is also a welfare loss, because the regulation that reduces the types of non-audit services restricts the audit firm's economies of scope related to these services. The shareholders would be better off if this loss is insignificant compared with the welfare gain from the truthful reporting and greater auditor effort.

\footnotetext{
${ }^{34}$ This alternative regulation would have the same effect as if the shareholders could commit $e x$ ante to not hiring the same audit firm for potential future consulting services. However, sequential rationality dictates that the shareholders would not honor such a commitment unless there were mechanisms to force them to do so.
} 
The second situation is that the scope of the non-audit service is reduced by a small amount such that the new consulting rent remains greater than the expected loss of an audit failure in the post-SOX period. This case is similar to the current model. The auditor will report truthfully, but his effort level becomes smaller than that in the pre-SOX era. However, this reduction in effort is mitigated by the fact that there is less consulting rent for the audit firm to pursue, due to the restriction on the scope of non-audit services. In the welfare analysis, the tradeoff will be between the welfare gain from truthful reporting and the welfare loss from both the reduced auditor effort and the loss of economy of scope related to the prohibited non-audit services.

In summary, the regulation that reduces the scope of non-audit services will introduce a loss of economy of scope related to the disallowed services. To the extent that the new consulting rent remains greater than the expected loss of an audit failure in the post-SOX era, the joint consideration of this other regulation will not qualitatively affect the key results of this study regarding the SEC's regulation on audit firms' sharing rules.

\subsection{Ethical Values and Reputational Concerns of Auditors}

The ethical values of auditors are not included in the model. Our oneperiod model also abstracts from auditors' reputational concerns. The consideration of ethics and reputation would not qualitatively affect our results insofar as the incentives for truthful reporting (including the expected legal liability cost, ethnical values, and reputational concerns) are less significant compared with the consulting profits. To see this, note that our analysis is a change analysis, i.e., we examine the change in auditor behavior induced by the SEC regulation. As ethics and reputational concerns remained the same before and after the regulation, they do not have interactions with the effects of SEC regulation on auditor behavior. 
The issue of auditor independence would disappear if auditors held sufficiently high moral standards and had significant concerns for reputation. Our analysis is useful in the situation where the ethnical values and reputation considerations were not sufficient to deter auditors from giving false opinions, which means that the issue of auditor independence was not mute prior to the SEC regulation. We believe that our model captures some of the realities that led to the recent regulatory reforms related to the auditing industry.

\section{Summary and Concluding Remarks}

This study examines the interactions among the SEC's regulation of auditor compensation, the sharing rules of audit firms, and the partners' various decisions. We focus on the case where the expected legal liability cost of audit failure is less than the profit from a potential future consulting task. We find that the optimal sharing rule awards the audit partner a proportion of the firm's consulting revenues to induce the audit partner's effort and reporting decisions that maximize the firm's collective interests. However, the optimal sharing rule also induces a lack of truthful reporting by the audit partner and results in a welfare loss. To restore truthful reporting, the SEC (2003) regulation prohibits audit firms from compensating audit partners based on consulting revenues. However, we show that this regulation can induce the partners in the audit firms to strategically change the way liability cost is shared, which results in a lower level of audit effort. We further show that this regulation can improve the welfare of the economy (i.e., the total payoff to shareholders and audit firms) if the legal liability cost of auditor litigation is sufficiently large. In this case, the welfare gain from the inducement of truthful reporting outweighs the welfare loss from the reduction of audit effort in the performance of audits.

Our findings have implications for regulators. Although the legal payment made by the audit firm to the client (shareholders of the company) in the event of 
audit litigation is determined by the court, the liability born by individual partners within the firm is determined by the partnership agreement. In this regard, the liability exposure of individual partners is at the firm's discretion through the firm's liability-sharing rule. Regulators such as the SEC and Public Company Accounting Oversight Board (PCAOB) might have the access to the partnership agreement as they need to enforce the regulation on the audit firm's sharing rule. This study may bring to the attention of regulators the unexplored impact of the regulation on the firm's liability-sharing rule and the auditor effort.

One limitation of this study is that we consider only the effects of knowledge spillover from auditors to consulting partners. In practice, the knowledge spillover can be bi-directional. High quality audits may lower the consulting cost, and the consulting partners' work, in turn, may benefit auditors in future audits, as auditors can also share the consulting-generated knowledge. ${ }^{35}$ The exploration of this bi-directional knowledge spillover and the sharing rules that would induce more complex partner cooperation in audit partnerships are interesting avenues for future research.

${ }^{35}$ We thank a reviewer for making this point. 


\section{References}

Asare, S., J. Cohen, and G. Trompeter. 2005. The effect of non-audit services on client risk, acceptance and staffing decisions. Journal of Accounting and Public Policy 24 (6): 489-520.

Ascioglu, A., S. P. Hegde, and J. B. McDermott. 2005. Auditor compensation, disclosure quality, and market liquidity: Evidence from the stock market. Journal of Accounting and Public Policy 24 (4): 325-354.

Balachandran, B. V., and R. T. S. Ramakrishnan. 1987. A theory of audit partnerships: Audit firm size and fees. Journal of Accounting Research 25 (1): 111-126.

Benston, G. J., and A. L. Hartgraves. 2002. Enron: what happened and what we can learn from it. Journal of Accounting and Public Policy 21 (2): 105-127.

Chan, D. 1999. "Low-balling" and efficiency in a two-period specialization model of auditing competition. Contemporary Accounting Research 16 (4): 609642.

Chan, D. 2009. An analysis of Section 201 of the Sarbanes-Oxley Act. Working paper, University of Hong Kong.

Chapin, D. H. 1992. Changing the image of the CPA. The CPA Journal 62 (12): 16-21.

Coase, R. H. 1937. The nature of the firm. Economica 4: 386-405.

DeAngelo, L. 1981. Auditor independence, 'low balling', and disclosure regulation. Journal of Accounting and Economics 3: 113-127.

Dye, R. A. 1993. Auditing standards, legal liability, and auditor wealth. The Journal of Political Economy. 101 (5): 887-914.

Dye, R. A. 1995. Incorporation and the audit market. Journal of Accounting and Economics 19: 75-114.

Frankel, R., M. Johnson, and K. Nelson. 2002. Non-audit fees paid to auditors: Do they lead to managed earnings? Directorship Jul/Aug: 6-8. Academic Research Library. 
Ghosh, A., S. Kallapur, and D. Moon. 2009. Audit and non-audit fees and capital market perceptions of auditor independence. Journal of Accounting and Public Policy 28 (5): 369-385.

Grossman, S. J. 1981. Nash equilibrium and the industrial organization of markets with large fixed costs. Econometrica 49 (5): 1149-1172.

Hurter, A. P., and P. Lederer. 1986. Competition of firms: Discriminatory pricing and location. Econometrica 54 (3): 623-640.

Kaplan, R. L. 2004. The mother of all conflicts: Auditors and their clients. Journal of Corporate Law 29 (2): 363-383.

Liu, X. 2002. Profiting sharing in audit partnerships. Ph.D. dissertation. The University of British Columbia.

Liu, X., and D. A. Simunic. 2005. Profit sharing in an auditing oligopoly. The Accounting Review 80 (2): 677-702.

Magee, R., and M. Tseng. 1990. Audit pricing and independence. The Accounting Review 65 (April): 315-336.

Pae, S., and S. Yoo. 2001. Strategic interaction in auditing: An analysis of auditor's legal liability, internal control system quality, and audit effort. The Accounting Review 76 (3): 333-356.

Revell, J. 2003. The fires that won't go out. Fortune 148 (8): 139.

Sarbanes, P., and M. Oxley. 2002. Sarbanes-Oxley Act of 2002. Pub. L. No. 107204, 116 Stat. 745., Congress, Washington, D.C.

Schwartz, R. 1997. Legal regimes, audit quality and investment. The Accounting Review 72: 385-406.

Securities and Exchange Commission (SEC). 2003. Strengthening the commission's requirements regarding auditor independence. Release Nos. 33-8183; 34-47265; 35-27642; IC-25915; IA-2103, FR-68. (http://www.sec.gov/rules/final/33-8183.htm).

Simunic, D. 1984. Auditing, consulting, and auditor independence. Journal of Accounting Research 22: 679-702. 
Smith, R., and D. Tidrick. 1997. The effect of alternative judicial systems and settlement on auditing. Review of Accounting Studies 2 (4): 253-281.

Tirole, J. 2002. The Theory of Industrial Organization. The MIT Press: Cambridge MA, London.

Wyatt, A. R. 2003. Accounting professionalism - they just don't get it. American Accounting Association annual meeting, Honolulu, Hawaii.

Zeff, S. 2003. How the U.S. accounting profession got where it is today: Part I. Accounting Horizons 17 (3): 189-205.

Zeff, S. 2003. How the U.S. accounting profession got where it is today: Part II. Accounting Horizons 17 (4): 267-286.

Zhang, P., and L. Thoman. 1999. Pre-trial settlement and the value of audits. The Accounting Review 74 (4): 473-491. 


\section{Appendix A: Table of Notation}

$n_{i}=$ the number of companies audited by Firm $i$, where $i \in\{\mathrm{A}, \mathrm{B}\}$;

$I=$ the required investment for the continued operation of a company;

$p=$ the probability of a manager being highly competent;

$R=$ the cash flow generated from a company with a highly competent manager;

$\varphi=$ the probability that a company with a less competent manager generates a cash flow of $R$;

$\pi=$ the cash flow generated from the consulting task for the shareholders;

$e=$ the audit effort of an auditor;

$k=$ the marginal cost of audit effort;

$\theta=$ the probability of the existence of a consulting task;

$v=$ the effort cost of performing the consulting task by the consulting partner;

$r=$ the effort cost of performing the consulting task by an outside consultant;

$l=$ the legal payment made by the audit firm to the shareholders in the case of auditor litigation;

$y^{a}=$ the audit partner's compensation;

$y^{c}=$ the consulting partner's compensation;

$f^{a}=$ the audit fee;

$f^{c}=$ the consulting fee;

$\lambda^{c}=$ indicator variable that equals one if the auditor obtains the consulting task and zero otherwise;

$\lambda^{l}:=$ indicator variable that equals one if auditor litigation occurs and zero otherwise,

$\alpha=$ the audit partner's share of the audit fee;

$\beta=$ the audit partner's share of the consulting fee;

$\gamma=$ the audit partner's share of the legal liability cost;

$c=$ the audit partner's expected personal cost of an audit;

$C=$ the firm's expected cost of an audit; and

$W=$ the welfare of each client and audit firm pair. 


\section{Appendix B: Proofs}

\section{Proof of Lemma 1}

Given that an audit partner is engaged to perform the audit for a given fee, we search for a sharing rule that induces the partners to take the actions that maximize the firm's payoff (i.e., minimize the firm's cost) for the audit.

(a) The consulting partner's bidding strategy

At Stage 6, if a consulting task arises, the client chooses the consultant who bids the lowest fee for the task. Note that the upper bound of the payoff that the firm can obtain from the competition for the consulting task is $(r-v)$, which is the difference in the cost of the task performed by an outside consultant or the consulting partner. The sharing rule that induces a bidding equilibrium that allows the firm to achieve the upper bound of payoff must satisfy

$$
\beta \leq(r-v) / r .
$$

For any given sharing rule, $\beta \leq(r-v) / r$, the consulting partner's break-even price for the consulting task is less than or equal to the competitor's cost, i.e., $v /(1-\beta) \leq r$. Given this sharing rule and the correct conjecture of the sharing rule by the outside consultant, the unique pair of equilibrium bidding strategies is that both players bid $r$, and the consulting partner wins the bid because his breakeven price (or the production cost) is smaller. The sharing rule $\beta \leq(r-v) / r$ constitutes a bidding equilibrium, because the firm cannot gain a greater consulting payoff by unilaterally changing the sharing rule, and neither can the outside consultant be better off by changing the bid of $r$. In equilibrium, the firm's consulting payoff achieves the upper bound of $r-v>0$. However, if $\beta>(r-v) / r$, then the audit firm will lose the bid for the consulting task.

(b) The audit partner's reporting strategy

At Stage 4, the audit partner issues an unqualified opinion when he finds no evidence of misstatements. When the audit partner detects a misstatement, the 
reporting strategy that maximizes the firm's payoff is to issue a qualified opinion if, and only if, a consulting task exists. To induce the audit partner to use this optimal reporting strategy, the sharing rule $\{\beta, \gamma\}$ must satisfy the following conditions:

$$
\begin{aligned}
& 0 \leq \gamma(1-\varphi) l, \text { if no consulting task exists; } \\
& \beta r>\gamma(1-\varphi) l, \text { if a consulting task exists where } r-v>(1-\varphi) l .
\end{aligned}
$$

(c) The audit partner's effort choice

At Stage 2, the optimal level of effort, which maximizes the firm's payoff (i.e., minimizes the firm's cost) of the audit, is determined by solving (3). As shown in the main text, the optimal effort level is

$$
e_{1}^{*}=\frac{(1-p)(1-\theta)(1-\varphi) l}{2 k} .
$$

In contrast, the audit partner chooses effort to solve (5). If the audit partner's effort choice is interior, then it equals

$$
e_{1}^{+}=\frac{(1-p)(1-\theta) \gamma(1-\varphi) l}{2 k} .
$$

Clearly, to induce the audit partner to expend the optimal level of effort (i.e., $e_{1}^{+}=e_{1}^{*}$ ), we require that $\gamma_{1}^{*}=1$. Given that $\gamma_{1}^{*}=1$, the only $\beta$ that satisfies (B1)(B3) for any given values of $r, v$, and $(1-\varphi) l$ is $\beta_{1}^{*}=(r-v) / r$. In other words, $\left\{\beta_{1}^{*}=(r-v) / r, \gamma_{1}^{*}=1\right\}$ is a unique sharing rule that induces the optimal partner behavior for the firm for any given values of $r, v$, and $(1-\varphi) l$. Q.E.D.

\section{Proof of Proposition 1}

Because the companies are identical and independent, considering the game for just one company suffices. Suppose that the shareholders of the company choose the auditor who bids the lowest audit fee, which will be shown 
later as the shareholders' equilibrium strategy. Let $\underline{f}^{a}$ be an auditor's break-even price for the audit. Consider the set of sharing rules $T=\left\{\alpha, \beta, \gamma \mid \alpha=c(\beta, \gamma) / C(\beta, \gamma), C(\beta, \gamma)=C\left(\beta_{1}^{*}, \gamma_{1}^{*}\right), c(\beta, \gamma)>0\right\}$ for an audit firm, where $C$ is the firm's cost of the audit (see (3)) and $c$ is the audit partner's personal cost of the audit (see (5)). For any given sharing rule $\{\alpha, \beta, \gamma\} \in T$, the firm's cost of the audit is minimized, and the audit partner's break-even price equals the firm's cost, i.e., $\underline{f}^{a}=c / \alpha=C$. Hence, the audit partner always bids in the interest of the firm in the competition for the audit task. It follows that the sharing rule maximizes the firm's payoff against any strategy of the rival firm.

The steps taken to show that $T$ is a set of dominant compensation strategies are outlined as follows. ${ }^{36}$ Fix a sharing rule $\left\{\alpha_{1}, \beta_{1}, \gamma_{1}\right\} \in T$. First, we can show that $\left\{\alpha_{1}, \beta_{1}, \gamma_{1}\right\}$ dominates any sharing rule $\left\{\alpha_{2}, \beta_{2}, \gamma_{2}\right\} \in$ $\left\{\alpha, \beta, \gamma \mid \alpha>0, C(\beta, \gamma)>C\left(\beta_{1}^{*}, \gamma_{1}^{*}\right), c(\beta, \gamma)>0\right\}$. The method is to show that there exists a biding strategy of the rival auditor such that the sharing rule $\left\{\alpha_{1}, \beta_{1}, \gamma_{1}\right\}$ yields a strictly greater payoff for the firm than $\left\{\alpha_{2}, \beta_{2}, \gamma_{2}\right\}$ does. Second, using a similar method, we can show that $\left\{\alpha_{1}, \beta_{1}, \gamma_{1}\right\}$ dominates any sharing rule $\left\{\alpha_{3}, \beta_{3}, \gamma_{3}\right\} \in\left\{\alpha, \beta, \gamma \mid 0<\alpha \neq c(\beta, \gamma) / C(\beta, \gamma), C(\beta, \gamma)=C\left(\beta_{1}^{*}, \gamma_{1}^{*}\right)\right.$, $c(\beta, \gamma)>0\}$. Third, we can show that $\left\{\alpha_{1}, \beta_{1}, \gamma_{1}\right\}$ dominates any sharing rule $\left\{\alpha_{4}, \beta_{4}, \gamma_{4}\right\} \in\{\alpha, \beta, \gamma \mid \alpha \leq 0$ or $c(\beta, \gamma) \leq 0\}$. Since $\left\{\alpha_{1}, \beta_{1}, \gamma_{1}\right\}$ is arbitrarily chosen from the set $T$, we know that $T$ is a set of dominant compensation strategies for the firm.

Clearly, the audit partners from the two firms that use dominant sharing rules have the same break-even price, which equals the firm's cost. Thus, the

\footnotetext{
${ }^{36}$ Details of the steps are omitted here for brevity, but are available from the author upon request (the detailed proof is provided to the editor and reviewers in the reviewer appendix).
} 
unique bidding equilibrium at Stage 1 is that the two audit partners bid the same audit fee that is equal to the firm's cost, i.e., $f_{1}^{a *}=C\left(\beta_{1}^{*}, \gamma_{1}^{*}\right)$. Given our assumed tie-breaking rule, the audit partners have an equal chance of winning the bid. This implies that the two partners have the same expected share of the audit market. Also note that a dominant sharing rule constitutes a bidding equilibrium for the consulting task at Stage 6, in which the consulting partner wins the task with the price $f_{1}^{c *}=r$.

From the shareholders' perspective, choosing the auditor who bids the lowest fee is the optimal strategy, given their posterior belief that an audit firm uses a sharing rule that minimizes the firm's cost of the audit. This posterior belief can be derived from the firm's equilibrium strategies based on Bayes' rule. We observe that on the equilibrium path $\operatorname{Pr}\left[C(\beta, \gamma)=C\left(\beta_{1}^{*}, \gamma_{1}^{*}\right), f^{a *}=C\left(\beta_{1}^{*}, \gamma_{1}^{*}\right)\right]=1$. Hence, conditional on the observed equilibrium audit fee $f^{a *}=C\left(\beta_{1}^{*}, \gamma_{1}^{*}\right)$, the shareholders' posterior belief $\operatorname{Pr}\left[C(\beta, \gamma)=C\left(\beta_{1}^{*}, \gamma_{1}^{*}\right) \mid f^{a^{*}}=C\left(\beta_{1}^{*}, \gamma_{1}^{*}\right)\right]=1$ obeys Bayes' rule.

The above arguments show that the firms' dominant sharing rules (from the set $T$ ) and the shareholders' strategies and beliefs that are specified in Parts (b) and (c) of Proposition 1 constitute a perfect Bayesian equilibrium.

Finally, note that $\left\{\alpha_{1}^{*}, \beta_{1}^{*}, \gamma_{1}^{*}\right\} \in T$, where $\beta_{1}^{*}=(r-v) / r, \gamma_{1}^{*}=1$, and $\alpha_{1}^{*}=c\left(\beta_{1}^{*}, \gamma_{1}^{*}\right) / C\left(\beta_{1}^{*}, \gamma_{1}^{*}\right)=1$. Furthermore, Lemma 1 shows that $\left\{\beta_{1}^{*}, \gamma_{1}^{*}\right\}$ is a unique sharing rule that minimizes the firm's cost of an audit for any given values of $r, v$, and $(1-\varphi) l$. Together, these imply that $\left\{\alpha_{1}^{*}, \beta_{1}^{*}, \gamma_{1}^{*}\right\}$ is a unique sharing rule that is a dominant compensation strategy for an audit firm for any given values of $r, v$, and $(1-\varphi) l$. Q.E.D. 


\section{Proof of Proposition 2}

Given that an audit firm is engaged to perform the audit for a given fee, we search for a sharing rule that can induce the partners of the firm to take actions that minimize the firm's expected audit cost.

(i) The consulting partner's bidding strategy

As shown in the proof of Lemma 1 , the sharing rule $\beta_{2}^{*}=0<(r-v) / r$ constitutes a bidding equilibrium at Stage 6 in which the consulting partner wins the consulting task with the bid at $r$. The audit firm's payoff from the consulting task achieves the upper bound of $(r-v)$.

(ii) The audit partner's reporting strategy

At Stage 4, given that the audit partner detects a misstatement and a consulting task exists, the auditor's expected payoff from the client if he issues an unqualified opinion is $\beta r-\gamma(1-\varphi) l=-\gamma(1-\varphi) l$, as $\beta=0$. Note that $\gamma$ must be positive in equilibrium, because if $\gamma \leq 0$, then the audit partner would bear no legal liability cost and thus have no incentive to exert effort in the performance of the audit, in which case the audit would have zero value. Hence, $-\gamma(1-\varphi) l<0$, which then implies that the auditor always reports truthfully.

(iii) The audit partner's effort choice

The effort level that minimizes the firm's cost is determined by solving the following problem:

$$
\operatorname{Min}_{e \in[0,1]} C=k e^{2}+(1-p)(1-e)(1-\varphi) l-[p+(1-p)(1-e)] \theta(r-v) .
$$

The optimal level of effort is

$$
e_{2}^{*}=\frac{(1-p)[(1-\varphi) l-\theta(r-v)]}{2 k} .
$$

Note that $e_{2}^{*}>0$, since by assumption $(1-\varphi) l>\theta(r-v)$. Moreover, $e_{2}{ }^{*}<e_{1}^{*}<1$ 
since $(1-\varphi) l-\theta(r-v)<(1-\theta)(1-\varphi) l$. This proves Part (b) of Proposition 2, as $e_{2}^{*}$ can be induced by the new sharing rule $\gamma_{2}^{*}=\frac{(1-\varphi) l-\theta(r-v)}{(1-\varphi) l}$. To see this, note that the audit partner's effort choice is determined by solving the following problem:

$$
\operatorname{Min}_{e \in[0,1]} c=k e^{2}+(1-p)(1-e) \gamma(1-\varphi) l
$$

The audit partner's optimal effort choice is

$$
e_{2}^{+}=\frac{(1-p) \gamma(1-\varphi) l}{2 k}
$$

Clearly, the audit partner is induced to make the firm's optimal effort choice only when $\gamma_{2}^{*}=\frac{(1-\varphi) l-\theta(r-v)}{(1-\varphi) l}$. Furthermore, comparing (B4) and (B5) reveals that if $\beta_{2}^{*}=0$ and $\gamma_{2}^{*}=\frac{(1-\varphi) l-\theta(r-v)}{(1-\varphi) l}$, then $c\left(\beta_{2}^{*}, \gamma_{2}^{*}\right)=C\left(\beta_{2}^{*}, \gamma_{2}^{*}\right)+p \theta(r-v)$. Thus, the audit-fee-revenue-sharing rule, $\alpha$, that equates the audit partner's break-price with the firm's audit cost is $\alpha_{2}^{*}=c\left(\beta_{2}^{*}, \gamma_{2}^{*}\right) / C\left(\beta_{2}^{*}, \gamma_{2}^{*}\right)=\left[C\left(\beta_{2}^{*}, \gamma_{2}^{*}\right)+p \theta(r-v)\right] / C\left(\beta_{2}^{*}, \gamma_{2}^{*}\right)>1$. Based on the same reasoning as in the proof of Proposition 1, we can show that the sharing rule that is characterized by $\alpha_{2}^{*}=\left[C\left(\beta_{2}^{*}, \gamma_{2}^{*}\right)+p \theta(r-v)\right] / C\left(\beta_{2}^{*}, \gamma_{2}^{*}\right), \beta_{2}^{*}=0$, and $\gamma_{2}^{*}=\frac{(1-\varphi) l-\theta(r-v)}{(1-\varphi) l}$ is the firm's dominant compensation strategy for any given values of $r, v$, and $(1-\varphi) l$. Other equilibrium results follow the same arguments as in the proof of Proposition 1. Q.E.D.

\section{Proof of Proposition 3}

The welfare of each client and audit firm pair before the regulation is given by

$$
W_{1} \equiv p[R+\theta(\pi-v)-I]+(1-p)\left(1-e_{1}^{*}\right)[\varphi R+\theta(\pi-v)-I]+(1-p) e_{1}^{*} \theta[\varphi R+(\pi-v)-I]-k e_{1}^{* 2} .
$$

The audit partner's effort and reporting decisions change in response to the regulation. As a result, the welfare changes to 


$$
W_{2} \equiv p[R+\theta(\pi-v)-I]+(1-p)\left(1-e_{2}^{*}\right)[\varphi R+\theta(\pi-v)-I]-k e_{2}^{* 2} .
$$

The change of welfare brought by the regulation is then given by

$$
\begin{aligned}
\Delta W & \equiv W_{2}-W_{1} \\
& =(1-p) e_{1}^{*} \theta[I-\varphi R-(\pi-v)]-(1-p)\left(e_{1}^{*}-e_{2}^{*}\right)[I-\varphi R-\theta(\pi-v)]+k\left(e_{1}^{* 2}-e_{2}^{* 2}\right) .
\end{aligned}
$$

Observe that $0<\sigma_{1} \equiv I-\varphi R-(\pi-v) \leq \sigma_{2} \equiv I-\varphi R-\theta(\pi-v)$. Since $\left(e_{1}^{* 2}-e_{2}^{* 2}\right)>0$, a sufficient condition for $\Delta W>0$ is that $e_{1}^{*} \theta \sigma_{1}-\left(e_{1}^{*}-e_{2}^{*}\right) \sigma_{2} \geq 0$. This inequality holds if and only if $l \geq \frac{(r-v) \sigma_{2}}{(1-\varphi)\left[(1-\theta) \sigma_{1}+\sigma_{2}\right]}$. To see this, note that substituting $\quad e_{1}^{*}=(1-p)(1-\theta)(1-\varphi) l / 2 k \quad$ and $e_{2}^{*}=(1-p)[(1-\varphi) l-\theta(r-v)] / 2 k$ into $e_{1}^{*} \theta \sigma_{1}-\left(e_{1}^{*}-e_{2}^{*}\right) \sigma_{2} \geq 0$ and simplifying terms yield ${ }^{37}$

$$
\begin{aligned}
& \frac{(1-p) \theta\left\{(1-\theta)(1-\varphi) l \sigma_{1}-[r-v-(1-\varphi) l] \sigma_{2}\right\}}{2 k} \geq 0 \\
& \Leftrightarrow(1-\varphi) l\left[(1-\theta) \sigma_{1}+\sigma_{2}\right]-(r-v) \sigma_{2} \geq 0 \\
& \Leftrightarrow l \geq \frac{(r-v) \sigma_{2}}{(1-\varphi)\left[(1-\theta) \sigma_{1}+\sigma_{2}\right]} .
\end{aligned}
$$

Therefore, the change of welfare, $\Delta W$, is positive when $l \geq \frac{(r-v) \sigma_{2}}{(1-\varphi)\left[(1-\theta) \sigma_{1}+\sigma_{2}\right]}$. Q.E.D.

\footnotetext{
${ }^{37}$ Also note that $\theta>0,0<p<1$, and $k>0$.
} 
Figure 1: Timeline of the Game

Stage 0: $\quad$ Partners in each firm decide on a sharing rule.

(Start of the period)

Stage 1: $\quad$ Audit partners from the two firms submit bids to the shareholders in competition for audit engagements.

Stage 2: $\quad$ Each audit partner expends effort for each audit engagement that is obtained.

Stage 3: $\quad$ For each company, a consulting task (if it exists) becomes known to the audit partner.

Stage 4: $\quad$ Each company's auditor issues an audit opinion.

Stage 5: Shareholders decide whether to invest in or liquidate a company depending on the audit opinion.

Stage 6: $\quad$ For each company in which shareholders decide to invest, if a consulting task exists, then the shareholders choose between the consulting partner of the audit firm and an outside consultant to perform the consulting task.

End of the period: The return of each company is realized, and legal payments are made from the audit firm to the shareholders if the company generates a low return.

Partners are compensated according to the pre-determined sharing rule. 
FIGURE 2: The Game Tree for the Audit Firm's Effort Choice Problem Given that $(r-v)>(1-\varphi) l$

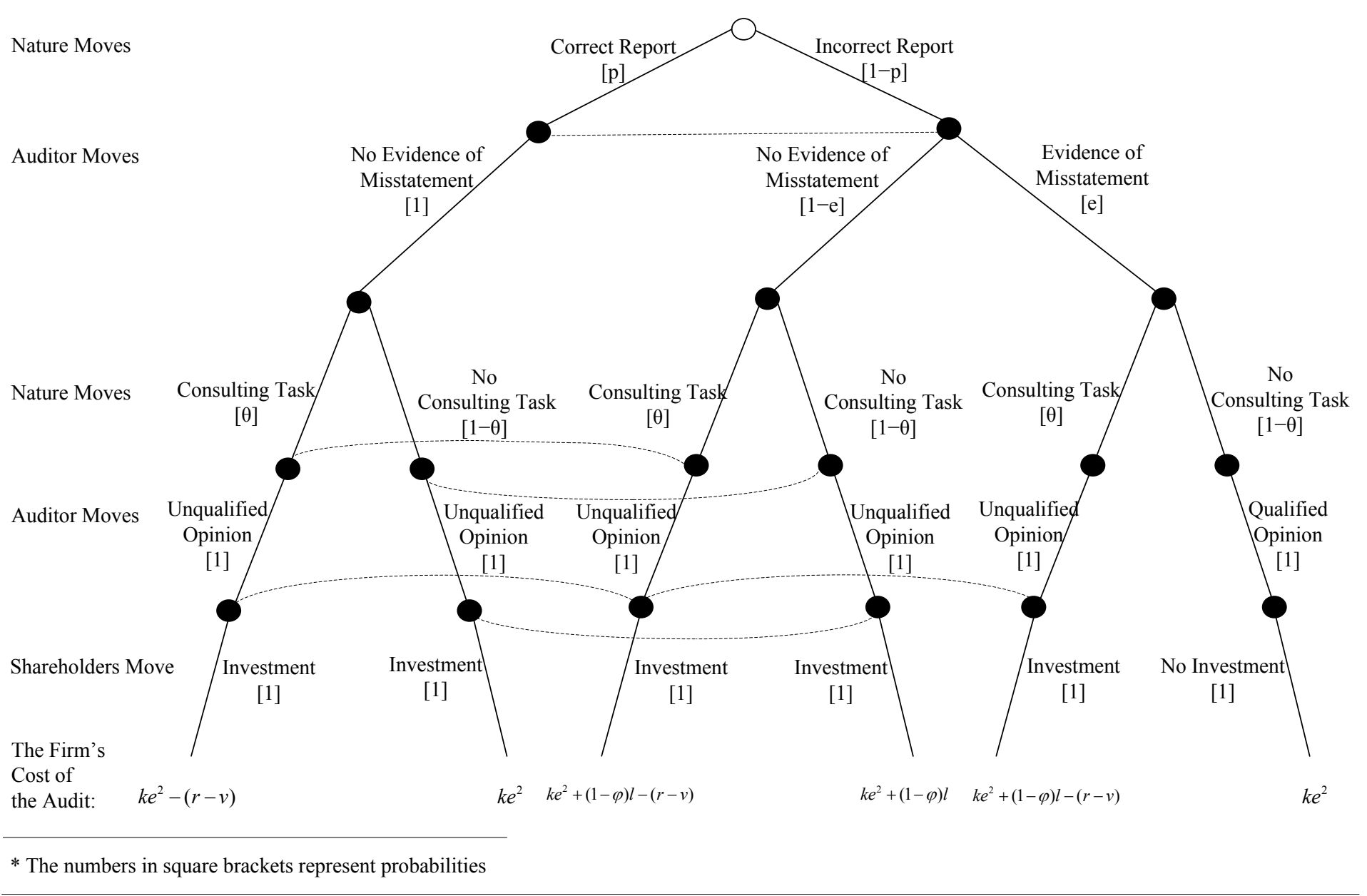

